\title{
Regulating Vertical Integration in Broadband: Open Access versus Common Carriage
}

\author{
CHRISTIAAN HOGENDORN *
}

Economics Department, Wesleyan University

\begin{abstract}
Broadband Internet involves two vertical relationships: the Internet Service Provider (ISP) requires both a physical conduit (e.g. telephone or cable television lines) and content. The ISP-conduit relationship has been subject to controversial unbundling regulation, but no such rules apply to the ISP-content relationship. We argue that regardless of whether ISPs are vertically integrated with conduits, they have incentives to create vertical restrictions on content. Foreclosure of ISPs by conduits may not increase and indeed could reduce these restrictions. Thus, telephone common carriage and Internet application neutrality may both be at odds with unbundling and "open access" policies.
\end{abstract}

\section{Introduction}

Broadband residential service is causing the convergence of products traditionally provided by telecommunications and television. This mixture has also caused a convergence, or one might say collision, of the regulatory paradigms associated with these industries. Much research has gone into these convergence issues, and we review it here. But our main focus is a second complication: intermediaries known as Internet Service Providers (ISPs) arose to make Internet connections available over conventional telephone lines, and these ISPs have become caught up in broadband regulatory policy.

The key to our analysis is that there are two relationships in broadband. First, the ISP must gain access to the residential household over a telephone or cable conduit. The ISPconduit relationship has received a tremendous amount of policy attention through unbundling or open access policies that seek to ensure non-discriminatory access of ISPs to conduits. Second, the ISP offers content of one type or another to its customers. We believe this ISP-content relationship has received much too little attention, and that in fact it is key to openness on the Internet.

In this context, "open" generally refers to a lack of vertical foreclosure, but since there are two vertical relationships, there are two types of openness. "Open access" refers to the

\footnotetext{
* 238 Church Street, Middletown, CT 06459. E-mail: chogendorn@wesleyan.edu I benefited from helpful discussions with Shane Greenstein and Taylor Reynolds. I thank guest editor Flavio Menezes and two anonymous referees for helpful comments. Alice Lam and Stephen Yuen provided able research assistance. All errors are of course my own.
} 
ability of an ISP to purchase access to the conduit, while "open protocols" or "open content" describes an ISP that is neutral with respect to content and applications. One can imagine four distinct scenarios: (i) open access, open content would allow a user to select any ISP on any conduit, and then use that ISP to access any content; (ii) Open access, closed content would allow a user to access any ISP over a conduit, but each ISP would to some degree offer proprietary content like America Online does; (iii) Closed access, open content would mean that there was just one broadband provider per conduit (as in cable/DSL competition in most places), but each conduit would offer unfiltered, neutral access to the Internet; (iv) The most limiting case is closed access and closed content, in which each conduit offers its own unique content.

We tackle this vertical structure of broadband in several stages. First, we review the ISP-conduit relationship and its associated unbundling and open access regulations. This will be familiar ground to many readers, because there has been a great deal of theoretical and, recently, empirical research addressing whether these regulations are socially beneficial. We believe that the preponderance of this work suggests that unbundling and open access inhibit both new, facilities-based investment in communications infrastructure and investment by incumbent telephone companies. That must be weighed against the benefit of increased entry and competition among ISPs.

Second, we discuss the antecedents of broadband regulation: telephone common carrier regulation and cable television contract carrier regulation. Our main point here is to show the very different objectives of the two. In telephone, the main policy goal was that each telephone customer should be able to call every other customer without discrimination. In cable, on the other hand, there was never any corresponding principle that each customer should be able to watch any television program he or she wanted.

Third, we discuss the relationship of the ISP to content. Compared with the ISPconduit relationship, this is much less researched. Perhaps this is because the ISP industry was formerly characterized by small, highly competitive firms that had no ability to control content, although America Online was always a very large exception. We argue that soon most ISPs will move in the direction of controlling content, either through exclusive contracts or through incompatible protocols. We give several examples, and discuss the reasons why ISPs have incentives to discriminate among content providers.

Finally we argue that policies which focus on the ISP intermediary do not promote common carrier outcomes. Regulating the ISP-conduit relationship does not achieve nondiscriminatory access to all end-users of the Internet. If indeed that is the goal, it is the ISP-content relationship that requires the regulation. In fact, the current system of unbundling and open access could, we argue, lead to a less common-carrier-like outcome than a system of no regulation.

\section{ISP-conduit relations: Unbundling and open access}

\subsection{The ISP}

Before moving further, we have to discuss what is an ISP. This turns out to be a complicated question, since the role has been changing. Indeed, Greenstein (forthcoming, pg. 14) notes that in the ISP industry, "No consensus arose about the optimal combination 
of service lines to carry, which is indicative of uncertainty about the appropriate business model for commercializing the service."

During the 1980s, there were several pre-Internet antecedents of the ISP. Bulletin board systems allowed customers to dial in over telephone lines using a modem to post messages and download files. The bulletin board was generally not interconnected with any larger network. Online service providers, including Prodigy, Genie, CompuServe, and later MSN and AOL, operated more comprehensive services accessed by modem. These services included stock quotes, e-mail, and bulletin boards. The online service providers had national coverage with telephone numbers in many cities, but they were not interconnected with other online service providers. Notwithstanding their limitations, they had become a $\$ 10$ billion industry by the late 1980s. (Ferguson, 2004)

With the advent of the Internet backbones, demand arose for residential access. ISPs acted as intermediaries between the consumer and the backbones. The earliest advertisements for ISPs appear in Boardwatch magazine in late 1993. In 1995 there was an explosion of entry, and the major online service providers began offering access to the Internet as well. (Greenstein, forthcoming) Because of the need to keep telephone dial-up calls local, ISPs needed several points of presence (POPs) in a local area. These POPs, and the equipment and connections to serve them, did not have any particular economies of scale, so many small firms were feasible.

O'Donnell (2001) lists the basic functions of an ISP: fundamental networking, application services, and customer relations. "Fundamental networking" includes assigning each user an Internet Protocol (IP) number, routing data packets to and from that user's computer, and access, that is, linking the customer's house with the ISP's location.

\subsection{Telephone vs. broadband access}

For a dial-up ISP, access was via the telephone network, and the only equipment supplied by the ISP was a modem bank at its location. For higher speed access, the two leading technologies are cable modems, operating over cable television wires, and digital subscriber lines (DSL) operating over conventional telephone lines. Two excellent descriptions of these technologies are Jackson (2002) and Chapter 4 in NRC (2002).

The development of broadband is challenging to ISPs in two ways. They must secure access to broadband infrastructure, which is the motivation behind open access regulation. They must also offer new services and differentiate their product in a new market environment.

The concern that cable and telephone companies will not allow ISPs access to their wires has led to a great deal of debate. There is theoretical reason to be concerned: Rubinfeld and Singer (2001) argue that broadband markets meet the conditions for vertical foreclosure to be profitable. And as Ferguson (2004) points out, the evidence on the ground is that the conduits do try to restrict access when they are able.

\subsection{Regulation of broadband access}

The regulation of ISP-conduit relations has differed greatly between telephone and cable television conduits. The FCC's 1999 implementation of the Telecommunications Act of 1996 established rules for unbundling of DSL services: incumbent telephone companies had to make "unbundled network elements" (UNEs) available that were able to carry DSL traffic. Also, they had to permit interconnection with their own DSL equipment and sell their DSL service at wholesale (thought not cost-based) pricing. (Speta, 2000) 
Most of these rules were reversed in a contentious decision by a split FCC in February 2003. In its order, the Commission "... eliminate[d] most unbundling requirements for broadband, making it easier for companies to invest in new equipment and deploy the high-speed services that consumers desire."' The decision did not completely do away with unbundling regulation for open access because it left open the authority of individual states to impose such regulations.

No such regulations applied to unbundling of cable television networks. In 1999, AT\&T's merger with cable giant Telecommunications Inc. (TCI) raised fear of a large, vertically integrated ISP. The Mount Hood Cable Regulatory Commission in Portland, Oregon required AT\&T to offer "open access" to its cable platform. ${ }^{2}$ This requirement would allow rival ISPs to lease cable facilities from AT\&T so as to provide independent Internet access services. Hazlett and Bittlingmayer (2003, para 70) note that "... the "open access' concept in cable lifts directly from the UNE regulations in telephony."

Although the Oregon requirement was struck down by a Federal court, the open access issue rose again when America Online (AOL) merged with Time Warner. The Federal Trade Commission stipulated the combined AOL-Time Warner must carry three competing ISPs over its cable platform in its merger approval.

The FCC took a dim view of this development. In a 2002 ruling, it concluded that cable broadband is an "information service" rather than a "telecommunications service". ${ }^{3}$ This means that cable broadband should not be subject to any open access requirements. This ruling essentially freed cable-TV companies that offer broadband Internet access from leasing their cables to competitors.

Notwithstanding these setbacks for open access and unbundling, various versions of these policies continue to be proposed (for example, Hundt, 2004; Ferguson, 2004).

\subsection{Arguments for and against unbundling and open access}

The primary motivation for open access and unbundling regulations is to prevent incumbent telephone and cable television companies from foreclosing access to their lines. This increases the incentives for new firms to enter the ISP industry. Regulation may also be needed after this entry occurs to prevent the infrastructure owner from "holding up" ISPs that rely on their facilities in order to do business.

Additionally, incumbents may not provide the same level of innovation as competitive ISPs sharing the infrastructure. Incumbents may seek to protect existing markets. For example, Hazlett and Bittlingmayer (2003) argue that cable television companies might be slow to introduce Internet video services in order to protect cable television revenues. Incumbents might also be less innovative simply due to more entrenched corporate cultures or less competitive pressures to attract new users (Lemley and Lessig, 2001).

Critiques of unbundling and open access center on reduced infrastructure investment. Regulation that increased incentives for entry over existing networks could undermine incentives for new, facilities-based entry. For example, a study by Crandall et al. (2004) showed that lower rates for unbundled network elements led to less facilities-based entry by competitive telephone companies.

\footnotetext{
${ }^{1}$ FCC Release 03-36, August 22, 2003, p.7.

2 Bryan Gruley, "Must AT\&T Give Internet Rivals Access to TCI's Network," Wall Street Journal, January 15, 1999.

${ }^{3}$ Yochi J. Dreazen, "FCC Ruling Frees Cable-TV Firms From Sharing Wires,” Wall Street Journal, March $15,2002$.
} 
Also, if vertical foreclosure is in fact profit maximizing, then unbundling and open access could distort the investment incentives of the incumbent conduit. Foros (2004) shows that in most cases, the incumbent has less incentive to invest in network quality when it must offer a regulated access price below the profit maximizing level. Hazlett and Bittlingmayer (2003) note that DSL started with a big head-start because cable lines needed significant upgrading for broadband. But DSL deployment was very slow, and appeared to follow cable broadband rollouts (see the FCC report Broadband Today, 1999). They attribute this to reduced incentives to invest in DSL due to more extensive unbundling regulation. They also conduct an event study of stock price responses to good and bad news for cable open access regulation and show that investors rewarded open access setbacks. Hausman (2002) argues that in Korea, where unbundling and open access have not been imposed, broadband penetration had grown extremely quickly, while in the U.S. the policy of asymmetric regulation has distorted the market and hampered DSL deployment.

A different critique is that unbundling and open access are a distortion of socially beneficial free-market incentives. Speta (2000) argues that telephone networks are subject to direct network externalities. These lead to market failures that can be ameliorated by mandatory service and interconnection rules. But broadband is characterized by indirect network effects. This may mean that, especially at first, access providers will also need to supply content in order to overcome a chicken and egg problem. More important, the monopoly provider has a stronger incentive to allow access to complementary goods when there are indirect network externalities.

An interesting critique by Hazlett (2002) is to note that the computer chip-maker Intel has a strong interest in enlarging the broadband market and making it more efficient. Yet it has no reason to be biased in favor of cable or DSL. Its position is that open access is unwise for both cable and telephone.

There is probably some truth to all of these arguments, so the policy-maker must judge which are the most important in any particular setting. One important note, though, is that these arguments all relate to the ISP-conduit relationship. Yet we noted that the most common definitions of "openness" on the Internet deal with the ISP-content relationship. These ideas of openness are rooted in the common carrier tradition which we turn to next.

\section{Common carrier regulation}

Common carriage has governed telephone policy since the early twentieth century, but its origins go back to ancient times. In the Roman Empire, the law imposed obligations on ship owners, innkeepers and stable keepers for reasonable public access. In England, early common law placed certain duties on businesses that were considered "public callings". Common carriers must offer service on demand to the public at large without unreasonable discrimination. Thus "common" in this context meant "open to serving the general public", a type of openness that seems more akin to open content and protocols that allow nondiscriminatory use for end users.

Noam (1994) notes that common carrier is not a synonym for public utility or regulated monopoly. Indeed the 1901 Supreme Court case Western Union Tel. Co. v. Call Publishing Company determined that telegraph had a common carrier obligation based on common law, not any explicit regulation. And he quotes U.S. v. Brooklyn Eastern District Terminal 
(1914), "Whether a carrier is a common carrier ... does not depend upon whether its charter declares it to be such, ... but upon what it does." The conditions are: (1) service is regular, (2) customers are not readily predictable and are changeable, (3) the carrier solicits business from the general public, and (4) law and regulations define responsibilities of parties rather than contracts.

Noam (1994, p.1) also argues that "Common carriage ... is of substantial social value. It extends free speech principles to privately-owned carriers. It is an arrangement that promotes interconnection, encourages competition, assists universal service, and reduces transactions costs."

Whether or not telephone service falls under these common carrier regulations has been a contentious issue. Thorne et al. (1995, p.292) say that

"Telecom providers and regulators engage in an endless minuet that moves dancers in or out of the circle called 'common carriage'." (Hazlett and Bittlingmayer, 2003, para 28)

Telecom service regulation was established in the Communications Act of 1934, which was modelled on the Interstate Commerce Act of 1887 and applied common carrier and public utility principles to telecoms. "[T]he 1934 act provided that 'all common carriers' engaged in wire communications shall 'furnish such communication service upon reasonable request therefore' and shall 'establish physical connections with other carriers.' ... The 1934 Act also imposed the other essential features of common carrier regulation: that the carrier's rates be just and reasonable, that the carrier not discriminate among customers, and that the carrier provide service solely pursuant to tariffs filed with a federal agency having the power to investigate rates, classifications, and practices of the carrier." (Speta, 2000, pp.62-63) Again, this is openness at the end-user level, what we have been calling open content.

Cable television has, with a few exceptions, never been subject to common carrier principles. Cable operators can choose to carry or not carry the channels they want. Content provider and carrier can negotiate independently and transact at different prices and under different restrictions. Cable was explicitly determined not to be a common carrier in the 1984 Cable Communications Policy Act, and this was reaffirmed in the 1996 Telecoms Act. The exception is the must carry rule for local TV channels, which was first an FCC rule, then overturned by the courts, then made law in the Cable Television Consumer Protection and Competition Act of 1992. (Hazlett and Bittlingmayer, 2003)

\section{ISP-content relations: Open access is not common carriage}

We believe that the essential policy goal of open access and unbundling regulations is to to extend common carrier principles to Internet access. For example, Owen and Rosston (2003, p.3) sum up the arguments for openness with three points: (i) "Anyone should be free to offer content on the Internet."; (ii) "No one, aside from the originator of the content, should be in a position to impede any user's access to any content, either directly or indirectly, through technical standards, access or pricing decisions."; (iii) "Local broadband access facilities should be common carriers - that is, should be required to transmit all content on nondiscriminatory terms."

Openness to content has certainly been important in the related context of cable television. Faulhaber (2002, p.243) writes that 
Future platform competition is likely to depend upon new entrants having access to all necessary content, both video and Internet, to realize scope economies. The success of the direct broadcast satellite platform as opposed to the cable platform has been attributed by some to the FCC's program access rules, due to a 2002 sunset rule. Continuing these rules so that new platform competitors have reasonable access to 'must have' programming reduces the entry barriers into the platform infrastructure market.

We argue here that the current open access and unbundling regulations do not achieve these objectives of openness to content. This is because ISPs themselves are not common carriers and have the ability and incentive to restrict content availability.

\subsection{ISPs are not common carriers}

The 1960s Computer Inquiry produced a distinction between "basic" services, subject to common carrier regulation, and "enhanced" services that involved data or interaction and were not subject to such regulation. The 1996 Act updated this terminology to "telecommunications services" and "information services". Though the language was initially unclear, ISPs and Internet content have been held to be information services. (Speta, 2000)

Most of the content customers currently access over the Internet is based on open standards: e-mail, world wide web, and file sharing. These standards were explicitly designed to be independent of the networks that carry the traffic. Lemley and Lessig (2001) have argued forcefully that this "end-to-end" principle needs to be continued. At the same time, they recognize that changes in technology are rapidly changing the type of content the ISP provides: "The functions performed by ISPs, however, are not fixed. They have no inherent nature. Hence as bandwidth changes from narrow- to broad-band, we should expect the range of services offered by ISPs to change. As deliverability becomes more critical in video services, for example, ISPs could compete based on caching services.” (pg. 941)

In addition to higher speed versions of narrowband content, many commentators expect new types of broadband content to emerge. NRC (2002, chapter 3) discusses likely forthcoming content, focusing on audio (streaming audio, music downloads, and VoIP) and video (streaming television, downloading files, and "telepresence"). Combinations and hybrids may be even more popular and innovate in the future.

Thus, ISPs could simply ignore the end to end principle by selectively making content available using routing technology. Or they could develop new types of content using proprietary technology that does not conform to end to end in the first place. We speak of these as exclusive and incompatible content respectively.

Exclusive content is based on open standards but is simply provided on different terms to different users. Television is the obvious example: while TV programming is technologically compatible with every cable and satellite network, the networks can and do allocate channels to TV programs that they choose and negotiate contracts with.

Many ISPs also offer some kind of exclusive content, such as a home page or portal site, and often provide set-up software that makes this page the default location in the customer's web browser. ISPs may also offer caching of content where the ISP stores copies of web pages or files at its own location so that they can be retrieved quickly. This reduces traffic on the ISP's backbone connection and reduces response time for the user. NRC (2002) notes that Cisco Systems produced a 1999 white paper promoting technology to allow cable companies to control content flows and arguing that this was essential for commercial success. 
Exclusive content on an ISP or cable television system is sometimes referred to as a "walled garden". This sounds limiting, but the NRC report Bringing Home the Bits (2002, p.191) notes that "A walled garden is not, per se, hostile to consumers, because it may lead to lower prices and increased content. The concerns about restricted choice or walled gardens stem in part from the contrast with the unfettered, unfiltered access ... that has traditionally characterized Internet services."

One recent example of exclusive content even on a narrowband ISP is Microsoft Network's relationship with Major League Baseball. Subscribers to MSN's dial-up service get free audio broadcasts of baseball games, a service which is also available to all Internet users for an extra fee. Another example was announced recently in broadband. Comcast and Disney plan to deliver news and children's programming through Comcast's broadband service. Broadband subscribers will get free content that normally costs $\$ 4.95$ a month. ${ }^{4}$ This is part of an overall Comcast strategy to use content as a weapon in competition with DSL providers.

Hogendorn and Yuen (2004) model the decision by content providers to bargain exclusively with just one ISP. They show that if content is sufficiently valuable (that is, it is "must-have" content), then its provider may benefit from being exclusive. These benefits are more likely to appear when there is some incompatibility between the ISPs as well.

Incompatible content is based on protocols and software that are closed and only operate on a particular ISP. This violates the end-to-end principle because the communications protocols are not neutral with respect to applications. America Online offers a large amount of content through its own interface, content not available to those accessing the Internet by other means.

Although this paper focuses on wired broadband access, exclusive and incompatible content also apply to wireless access. In wireless there is a carrier that runs the network (for example, Verizon Wireless and T-Mobile), in some cases a reseller that has similarities to an ISP (for example, Virgin Wireless or the new ESPN Mobile service ${ }^{5}$ ), and various content firms offering wireless applications (for example, Jamdat Mobile, maker of a bowling game, which recently had an extremely successful stock offering ${ }^{6}$ ).

Wireless carriers have a tight hold on the content that appears on their phones. Indeed their control and their ability to charge for content via customers' phone bills has been touted as a major business advantage of wireless carriers over wireline ones. Currently, for example, Verizon Wireless offers a service called Get It Now to its customers that allows them to download various applications for their phone. Examples include ring tones, games, weather maps, and traffic reports. These applications typically cost about four dollars per month, billed by Verizon on the customer's monthly bill. Verizon has control over which content firms appear on this service, although at present it does seem to be allowing at least some competition. For example, there are two traffic reporting applications and three giving weather forecasts.

Because wireless is growing quickly and involves tighter integration of the network with the content provider, there is good reason to expect that issues of openness will arise there too. As in wired access, there are questions of how open the network is both to resellers and to content firms. There is a good chance that these issues will play out

\footnotetext{
${ }^{4}$ Peter Grant, “Comcast, Disney Team Up on Internet Deal,” Wall Street Journal, July 21, 2004, p.B1.

5 Jesse Drucker and Bruce Orwall, "New Game Plan: ESPN to Enter Cellular Market," Wall Street Journal, December 2, 2004, p.B1.

${ }^{6}$ Lee Gomes, “Tech's Next Big Thing?” Wall Street Journal, November 8, 2004, p.B1.
} 
differently in wireless, because the starting conditions are so different from wireline. There is already substantial facilities-based competition between wireless networks, reseller arrangements have been negotiated voluntarily in the private market, and there is no history of common carriage or end-to-end with regard to wireless applications. Nevertheless, the framework we describe in this section should be equally applicable in the wireless arena.

\subsection{ISPs have incentives to restrict content}

The most straightforward answer as to why an ISP would restrict content is simply that it has a better product to offer that way. AOL, for example, was able to offer web-like content before the web became available, and even afterward it was arguably an easier service to use. This is the reasoning behind what Farrell and Weiser (2004) call "internalizing complementary externalities", or ICE. ICE says that a "... platform monopolist has an incentive to favor whichever form of organization of applications is most efficient (or delivers the most value to users)." (pp.20-21) The theory is associated with the Chicago School of antitrust economics. It still involves content restrictions, but at least they are efficient.

Recent theory suggests that ICE will fail to hold in broadband Internet. Farrell and Weiser give a number of reasons for this. Among those that seem particularly relevant to our argument are the following:

Price discrimination: control over applications and platform can help with various bundling strategies. This is why Ferguson (2004, p.28) calls the prevailing system of purchasing content in a bundle from a cable or telephone company "significantly dysfunctional".

Protection against entry: control over content may protect the platform against entry in its main market. Microsoft has been repeatedly accused of protecting its Windows operating system monopoly in this way. Ferguson (2004) argues that an open architecture would undermine the cable television content business by making it easier for others to distribute video. Indeed, he suggests that cable and DSL operators have incentives to collude to keep broadband slow so as to protect their existing revenue streams.

Rubinfeld and Singer (2001) suggest two ways that exclusive content can protect against entry. First, the ISP could refuse to carry other ISPs' content in order to benefit its own. If this worked, it would reduce economies of scale at other content firms and some would exit the market as in Whinston (1990). This argument was the basis for the 1996 consent decree for the Time Warner/Turner merger. Second, the ISP could refuse to allow its content to be available on other ISPs. This would inhibit entry of other ISPs since they would have fewer products to sell, as in Carlton (2001).

Regulatory burdens: There is an option value to maintaining a closed platform, since opening a closed platform rarely invites regulatory scrutiny whereas closing an open one often does. Also, providing open access in one market may lead to calls for open access in other, related markets.

Indeed, Hazlett and Bittlingmayer (2004) explain the slow speed of cable broadband based on regulatory risk. They ask why operators do not allocate more spectrum to broadband. After all, revenue per channel is much higher for the single broadband channel than for the average TV channel, much less the marginal TV channel. The answer in their minds is that cable operators want to make sure to avoid common carrier regulation. "The separation of content and conduit dramatically lowers the transactions costs associated 
with imposing common carrier regulation. This reality has been long reflected in public policies that have attempted to limit common carrier rules (and rate regulation) to open access platforms." (para 29) An example is radio versus telephone.

Incomplete complementarity: if applications have other uses, for example, on cell phones or via Wi-Fi, there really is more than one source of profit from exclusive content relationships. Profits from related products already are important in the vertically integrated cable and telephone industries.

We caution that to some degree, all four of these arguments are still in the future. This is aptly put by Owen and Rosston (2003, p.26), who say that "... cable operators' so-farnot-very-successful efforts to offer upstream services tailored to the special features of broadband are better understood as attempts to remedy the failure of independent ISPs and content providers to provide such service than as an attempt to monopolize or foreclose any market."

Also, some ISPs are in fact offering broadband connections that are not bundled with other services. Many DSL providers, for example, currently offer plain high speed Internet Protocol connections (though often conventional telephone is bundled with the package). In Britain, British Telecom offers a wholesale broadband service called Bitstream that is available for bundling with any ISP. In France, competition over the speed of access has predominated. ${ }^{7}$ If services like this come to be the industry standard, then the concerns we have raised will not matter.

\subsection{Competition between ISPs does not imply common carrier behavior}

Since ISPs are not common carriers themselves, the only way open access policy will achieve common carrier outcomes is indirect. If open access increases competition among ISPs, then perhaps this will lead each ISP to remain wide open to content like the dial-up ISPs of the past. Shelanski (2002, p.191) puts this nicely by saying:

... the relationship between open access and preventing foreclosure of Internet content and applications is quite indirect. It is not necessarily true that competition among cable modem ISPs will prevent any one of them from gaining market power and either blocking some non-proprietary applications from reaching its subscribers or blocking access to its proprietary applications for subscribers of competing ISPs.

Speta $(2000$, p.87) argues that "The equilibrium amount of open access - that is, the amount of access that maximizes total returns to the platform provider, taking into account network externalities and other characteristics of market demand - may include fewer information service providers than had the broadband access platform been subject to perfect competition."

Hogendorn (2004) presents a formal model of ISPs' incentives to offer content and concludes that the relationship between open access regulation and content provision is ambiguous. The essentials of the argument can be understood from Figure 1. On the horizontal axis is the number of content firms offered by an ISP. For a traditional dial-up ISP, there were no restrictions, so the number was all the way to the right in the graph. But as we argued above, broadband ISPs could practice some restrictions.

The ISP's decision to offer content depends on how much surplus the content generates. One possibility is that the total surplus from offering content is shown by the curve $S_{1}$. In this case, offering more content always generates more total surplus. If the ISP

\footnotetext{
${ }^{7}$ Richard Medcalf and Stéphane Piot, "Competitive Broadband Markets: Lessons from France,” Analysys Consulting, February 2004. http://www.analysys.com/default acl.asp?Mode=article\&iLeftArticle=1506
} 
can appropriate some fraction of this surplus to itself through subscription fees to consumers, access fees to the content firms, or advertising, then it has every incentive to offer as much content as possible. This is very much in line with the ICE argument discussed earlier.

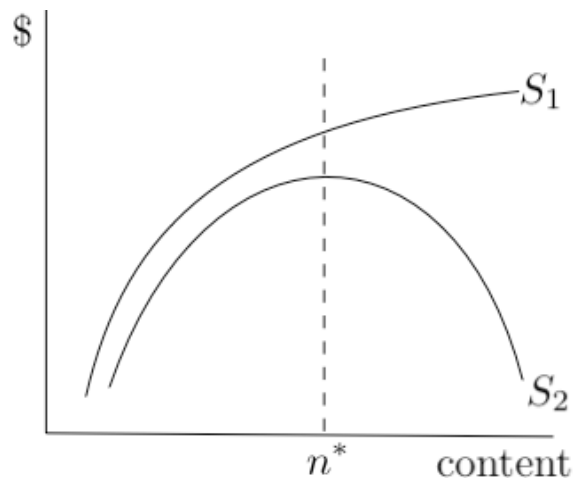

Figure 1: Total surplus from broadband

However, there is reason to believe that the relevant curve looks more like $S_{2}$. Eventually adding more content causes decreasing surplus. We imagine two reasons why this could happen. The first is that there are fixed set-up costs for the content but decreasing benefits of variety to consumers. This would imply that after some point, the additional content would primarily steal business from other content rather than expand the market, as in Mankiw and Whinston (1986).

The other reason is that the total surplus curve from a social planner's point of view may in fact look like $S_{1}$, but the portion of that surplus that the ISP can appropriate declines like $S_{2}$. For example, increasing content will generally shift surplus from producers (who must compete harder) to consumers (who like the lower prices and greater variety). But it may not be possible to price discriminate among consumers as easily as among producers, so the share of total surplus available to the ISP actually falls beyond some point. Rochet and Tirole (2004) describe similar tradeoffs for any "two-sided network" that sells to two different types of customers.

In this case, the ISP faces a tradeoff. All other things equal, it would offer the quantity of content $n^{*}$ that maximizes surplus. However, consumers like content, so the more content an ISP offers, the greater its market share. Hogendorn shows that $K$ ISPs can achieve a symmetric equilibrium where each one offers some quantity of content that is higher than $n^{*}$. Further, the more ISPs there are, the more fiercely they compete for consumers, and therefore the more content they offer.

So far, this suggests that open access and unbundling, by making ISP entry easier, really do promote a common carrier-like outcome. But there is a countervailing force. Another reason to compete hard for consumers is to sell them additional services. For example, a vertically integrated ISP/conduit could sell a consumer a bundle of cable television, telephone, and broadband Internet. This is often referred to as the "triple play" and has recently inspired alliances between AT\&T and cable companies on the one hand and DSL and satellite TV providers on the other. With a triple play, a consumer would be 
that much more valuable and worth competing for. In the model, the more services an ISP can offer, the more content it will want to offer in order to attract consumers.

But this raises a problem for open access and unbundling. By separating the different lines of business, these regulations could decrease the overall incentive to sign up an additional subscriber. Thus, it is possible for open access to reduce the incentive of ISPs to offer content. Put another way, applying common carrier principles to the ISP-conduit relationship could actually reduce common carrier behavior in the ISP-content relationship.

The types of evidence one would need to settle this issue are the entry costs of ISPs and conduits and the operating profits per household of Internet and non-Internet (for example, telephone and TV) services. If ISPs have low entry costs like under dial-up, then open access and unbundling would almost surely promote content. But if ISPs are becoming larger and more differentiated (à la AOL), entry costs could rise dramatically. And if nonInternet services generate relatively high profits compared to Internet services, then open access and unbundling could have no effect or even decrease content. We believe this high-entry-cost, high-non-Internet-profits case is quite plausible - thus our concern that these policies may not be an effective way to achieve common carrier outcomes.

\section{Conclusion}

This paper analyzes unbundling and open access regulation of broadband service by telephone and cable companies. We described the ways in which these policies differ from common carrier regulation. The principle difference is that common carrier ensures nondiscriminatory treatment of end-users, whereas open access simply prevents foreclosure of ISPs by vertically integrated conduits. But we then argued that ISPs have incentives to discriminate among content, and we described a model in which open access regulation could potentially increase rather than decrease these incentives. We conclude, therefore, that open access and unbundling may not be very effective at maintaining the open architecture of the Internet.

\section{$6 \quad$ References}

Carlton, D. (2001) “A General Analysis of Exclusionary Conduct and Refusals to Deal Why Aspen and Kodak are Misguided," Antitrust Law Journal, 68: 659-683.

Crandall, R. W., A. T. Ingraham, and H. J. Singer (2004) "Do Unbundling Policies Discourage CLEC Facilities-Based Investment," Topics in Economic Analysis and Policy, Vol. 4: No. 1, Article 14.

Farrell, J. and P. Weiser (2003) "Modularity, Vertical Integration, and Open Access Policies: Towards a Convergence of Antitrust and Regulation in the Internet Age," Harvard Journal on Law and Technology, 17: 85-134. 
Faulhaber, G. (2002) "Broadband Deployment: Is Policy in the Way?" in R. Crandall and J. Alleman (ed.) Broadband: Should We Regulate High-Speed Internet Access? Washington, DC: AEI-Brookings Joint Center for Regulatory Studies.

Ferguson, C. (2004) The Broadband Problem. Washington: Brookings Institution Press.

Foros, O. (2004) "Strategic Investments with Spillovers, Vertical Integration, and Foreclosure in the Broadband Access Market," International Journal of Industrial Organization, 22: 1-24.

Greenstein, S. (forthcoming) "The Economic Geography of Internet Infrastructure in the United States," in Martin Cave, Sumit Majumdar, Ingo Vogelsang (ed.) Handbook of Telecommunications Economics, Volume II.

Hausman, J. (2002) "Internet-Related Services: The Results of Asymmetric Regulation," in R. Crandall and J. Alleman (ed.) Broadband: Should We Regulate High-Speed Internet Access? Washington, DC: AEI-Brookings Joint Center for Regulatory Studies.

Hazlett, T. (2002) "Regulation and Vertical Integration in Broadband Access Supply," in R. Crandall and J. Alleman (ed.) Broadband: Should We Regulate High-Speed Internet Access? Washington, DC: AEI-Brookings Joint Center for Regulatory Studies.

Hazlett, T. and G. Bittlingmayer (2003) "The Political Economy of Cable 'Open Access'," Stanford Technology Law Review 4. http://stlr.stanford.edu/STLR/Articles/03_STLR_4.

$$
\text { http://stlr.stanford.edu/STLR/Articles/03_STLR_4 }
$$

Hogendorn, C. (2004) "Broadband Internet: Open Access and Content Competition," Working Paper, Wesleyan University. http://chogendorn.web.wesleyan.edu/oa.pdf.

Hogendorn, C. and K. Yuen (2004) "Platform Competition with 'Must-Have' Components," Working Paper, Wesleyan University. http://chogendorn.web.wesleyan.edu/must have.pdf.

Hundt, R. (2004) "The Ineluctable Modality of Broadband," Yale Journal on Regulation, 21: $239-259$.

Jackson, C. (2002) "Wired High-Speed Access," in R. Crandall and J. Alleman (ed.) Broadband: Should We Regulate High-Speed Internet Access? Washington, DC: AEIBrookings Joint Center for Regulatory Studies.

Lemley, M. and L. Lessig (2001) "The End of End-to-End: Preserving the Architecture of the Internet in the Broadband Era," UCLA Law Review, 48: 925-972.

Mankiw, N. G. and M. Whinston (1986) "Free Entry and Social Inefficiency," RAND Journal of Economics, 17: 48-58.

National Research Council (NRC) (2002) Broadband: Bringing Home the Bits. Washington: National Academy Press. 
O'Donnell, S. (2001) "Broadband Architectures, ISP Business Plans, and Open Access," in B. M. Compaine and S. Greenstein (ed.) Communications Policy in Transition: The Internet and Beyond. Cambridge and London: MIT Press in association with the Telecommunications Policy Research Conference.

Owen, B. and G. Rosston. (2003) "Local Broadband Access: Primum Non Nocere or Primum Processi? A Property Rights Approach," AEI-Brookings Joint Center for Regulatory Studies. http://www.aei-brookings.org/admin/authorpdfs/page.php?id=285.

Rochet, J.-C. and J. Tirole (2004) "Two-Sided Markets: An Overview," IDEI Working Paper. http://idei.fr/doc/by/tirole/rochet tirole.pdf.

Rubinfeld, D. and H. Singer (2001) "Vertical Foreclosure in Broadband Access?" Journal of Industrial Economics, 49: 299-318.

Shelanski, H. (2002) "Competition and Regulation in Broadband Communications," in R. Crandall and J. Alleman (ed.) Broadband: Should We Regulate High-Speed Internet Access? Washington, DC: AEI-Brookings Joint Center for Regulatory Studies.

Speta, J. (2000) "Handicapping the Race for the Last Mile? A Critique of Open Access Rules for Broadband Platforms," Yale Journal on Regulation, 17: 39-91.

Thorne, J., P. Huber, and M. Kellogg (1995) Federal Broadband Law. New York: Aspen Publishers.

Whinston, M. (1990) "Tying, Foreclosure, and Exclusion," American Economic Review, 80: 837-859. 